\title{
Preliminary Study on Acoustic Detection of Faults Experienced by a High-Bypass Turbofan Engine
}

\author{
Devin K. Boyle \\ NASA Armstrong Flight Research \\ Center
}




\section{Outline}

- Background on VIPR research

- Introduction to VIPR acoustics research objectives

- Motivation

- Test setup

- Research engine

- Preliminary detection of simulated failures

- Future work

- Conclusion 


\section{VIPR Background}

- Vehicle Integrated Propulsion Research (VIPR) project currently in Phase III of ground-based engine testing

- The project is using F117-PW-100 engines (military derivative of PW 2000 used on the Boeing 757) in the 40k-lb thrust class

- Engines are representative of typical high-bypass commercial turbofans

- VIPR is a way to introduce faults that would otherwise be prohibitive 


\section{VIPR Overview}

Vehicle Integrated Propulsion Research (VIPR) engine tests to support the research and development of Engine Health Management Technologies for Aviation Safety Engine testing is a necessary and challenging component of Aviation Safety technology development.

Partnerships make it possible.
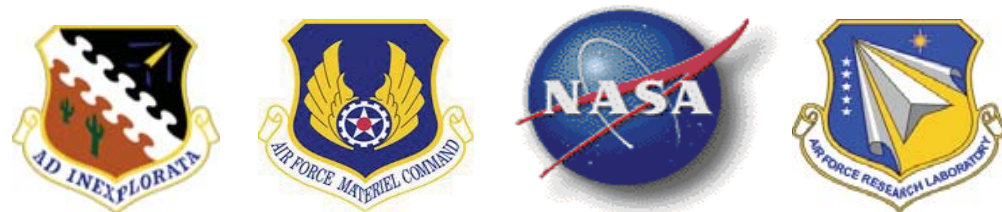

Fiber Optic

Dynamic Pressure Sensors
Temperature

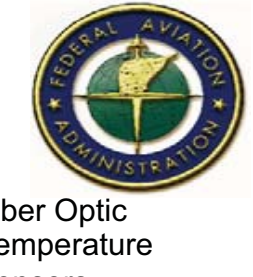

Sensors

Test Objectives:

Demonstrate capability of advanced health management technologies for detecting and diagnosing incipient engine faults before they become a safety impact and to minimize loss of capability

Approach:

Perform engine ground tests using high-bypass transport engine

- Normal engine operations

- Seeded mechanical faults

- Seeded gas path faults

- Accelerated engine life degradation through volcanic ash ingestion testing

Partnerships:

- NASA

- US Air Force

- Federal Aviation Administration

- Pratt \& Whitney

- GE

- Rolls-Royce

- United States Geological Survey

- Boeing

- Makel Engineering

- Others in discussion
Model-based gas path diagnostic architecture Acoustic Engine Health Monitoring

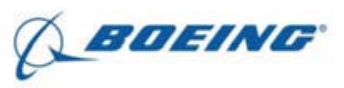

UUSGS

SDA and High Freq Vibration Sensors

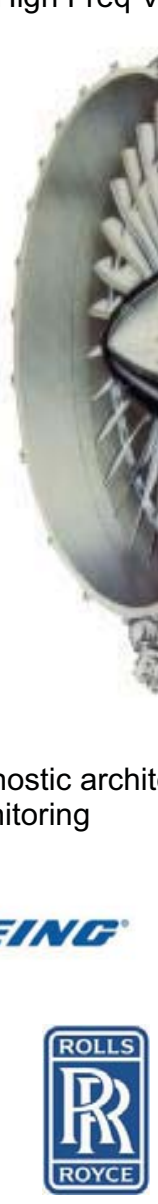

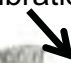

1 Microwave Tip Clearance Sensors

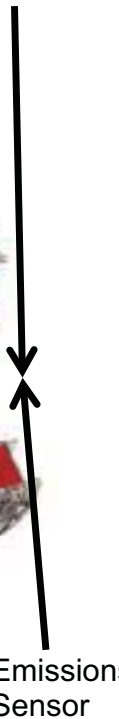

Thin Film Sensors

SDA and High Freq Vibration Sensors

Pratt \& Whitney

AUnited Technologies Company
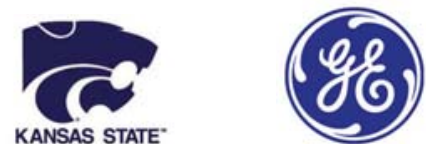

MAKEL 


\section{VIPR III Overview}

- VIPR III Test Objectives (Summer 2015)

- Engine Health Management (NASA):

- Initial steps toward EHM sensor fusion with Advanced Sensors

- Demonstrate capability of advanced health management technologies for detecting and diagnosing incipient engine faults before they become a safety impact and to minimize loss of capability

- Bleed Air Environment Testing (Boeing and Partners)

- To evaluate and characterize bleed air sensors, sampling and purification technologies in a relevant operating environment

- Volcanic Ash Ingestion Testing (AFRL and Partners)

- Run engine to end of life

- To improve understanding of the effect on the engine of several hours of exposure to low to moderate concentrations of volcanic ash

- Determine how well engine degradation from volcanic ash is detected with an expanded engine health management system

- Pratt \& Whitney Testing

- VIPR III is possible with the combined efforts/resources of the consortium 


\section{VIPR Acoustics Research}

- Goal: Characterize the engine core, fan, and exhaust acoustics under nominal and off-nominal/ seeded fault conditions

-Objective: Obtain engine core, fan, and exhaust acoustic health monitoring (AHM) data under nominal and off-nominal / seeded fault conditions

- Faults introduced during VIPR II included the simulated failures of the engine station 2.5 and $14^{\text {th }}$ stage bleed valves to their failsafe positions 


\section{Motivation}

- The use of acoustics, if proven successful in detecting and potentially identifying faults, can progress toward condition-based maintenance

-Ultimate goal is detection and eventual identification of common faults

- External acoustic measurements of engines is a simple and non-intrusive inspection process

- Additionally, microphones may characterize the progression of engine operational degradation

- System doesn't have to survive the harsh environment of the aircraft 


\section{Test Setup}

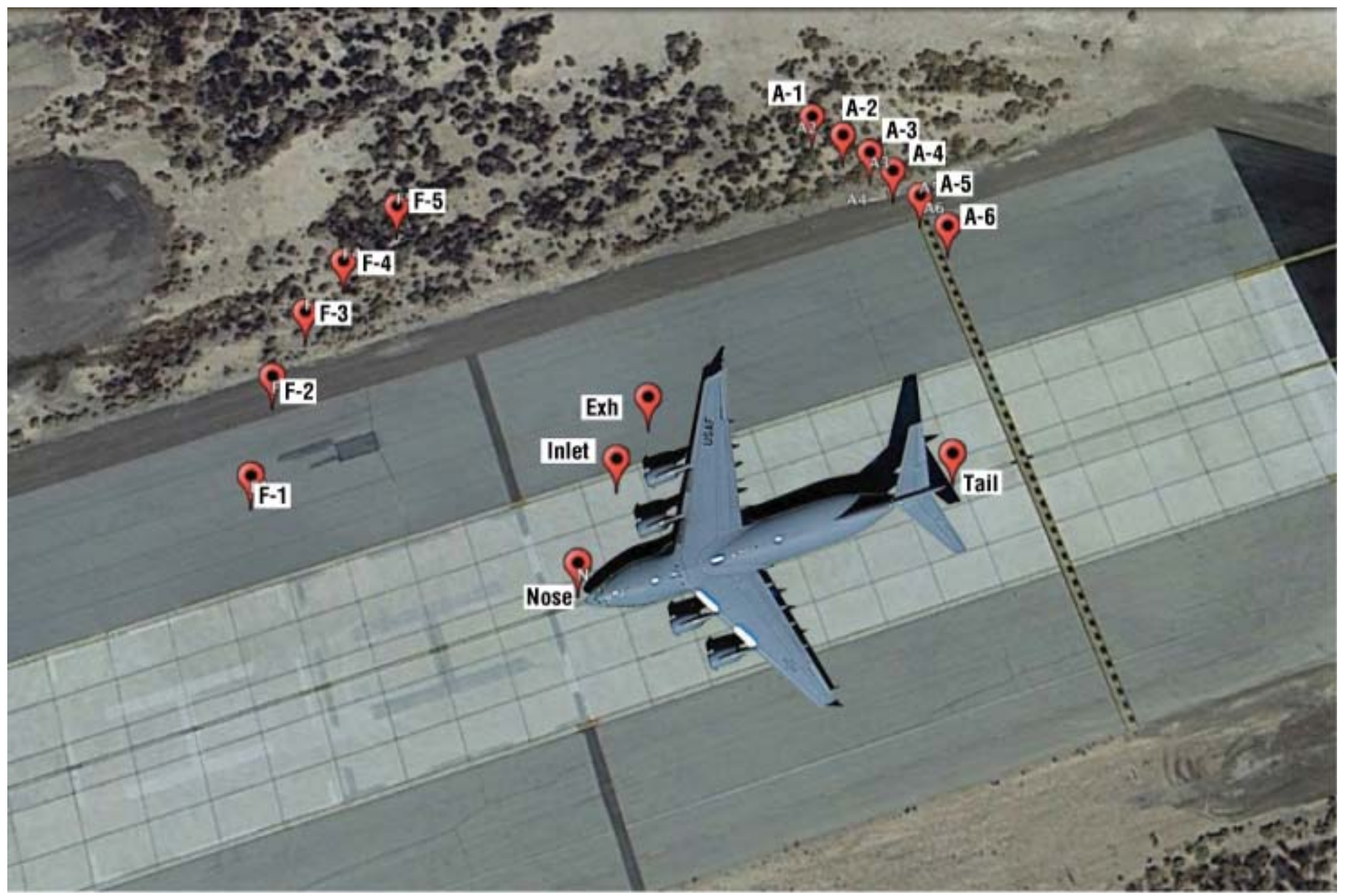

- Image courtesy Google earth 


\section{Test Setup (Continued)}

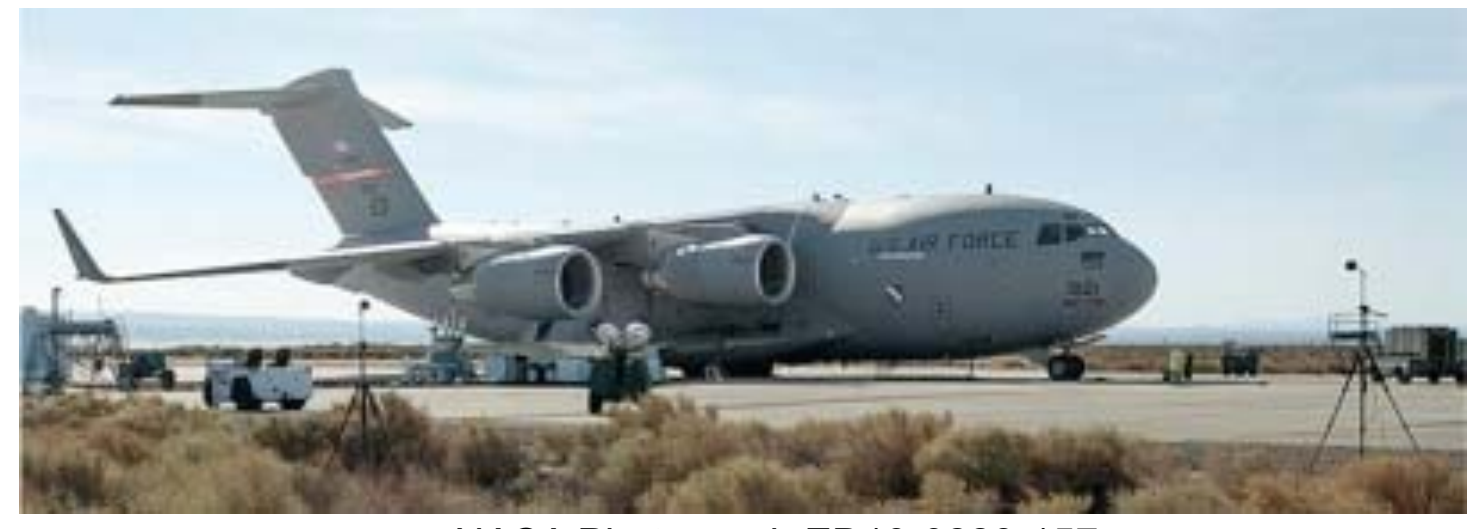

NASA Photograph ED13-0228-157

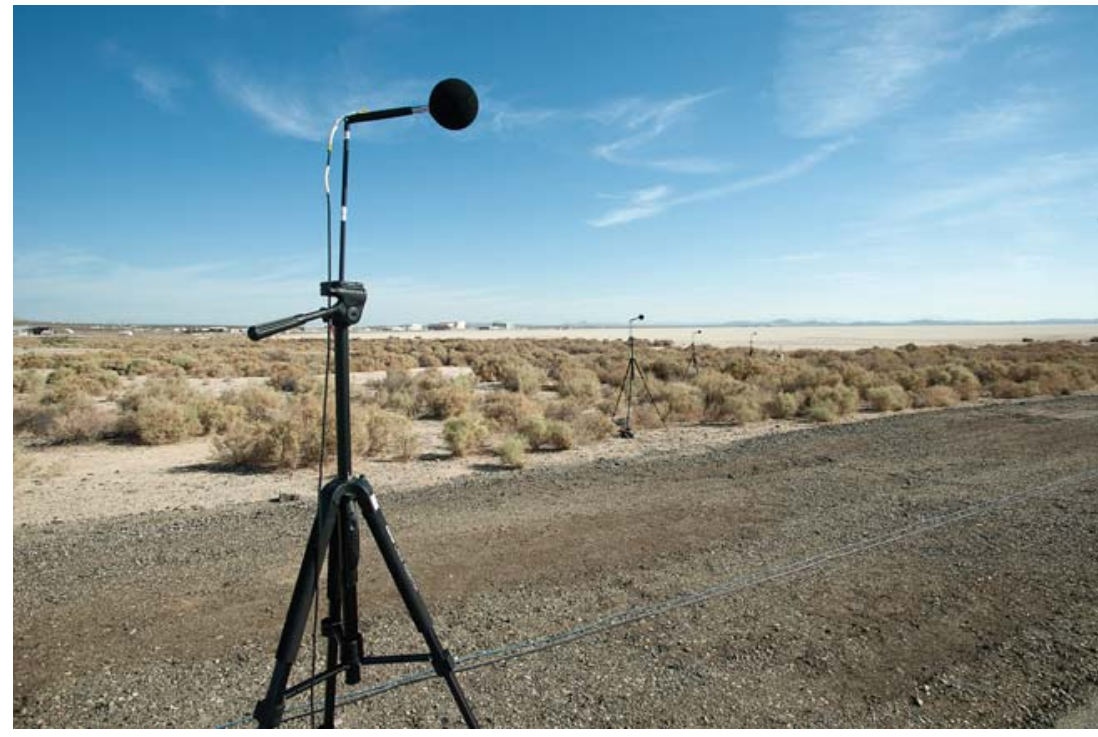

NASA Photograph ED13-0228-156

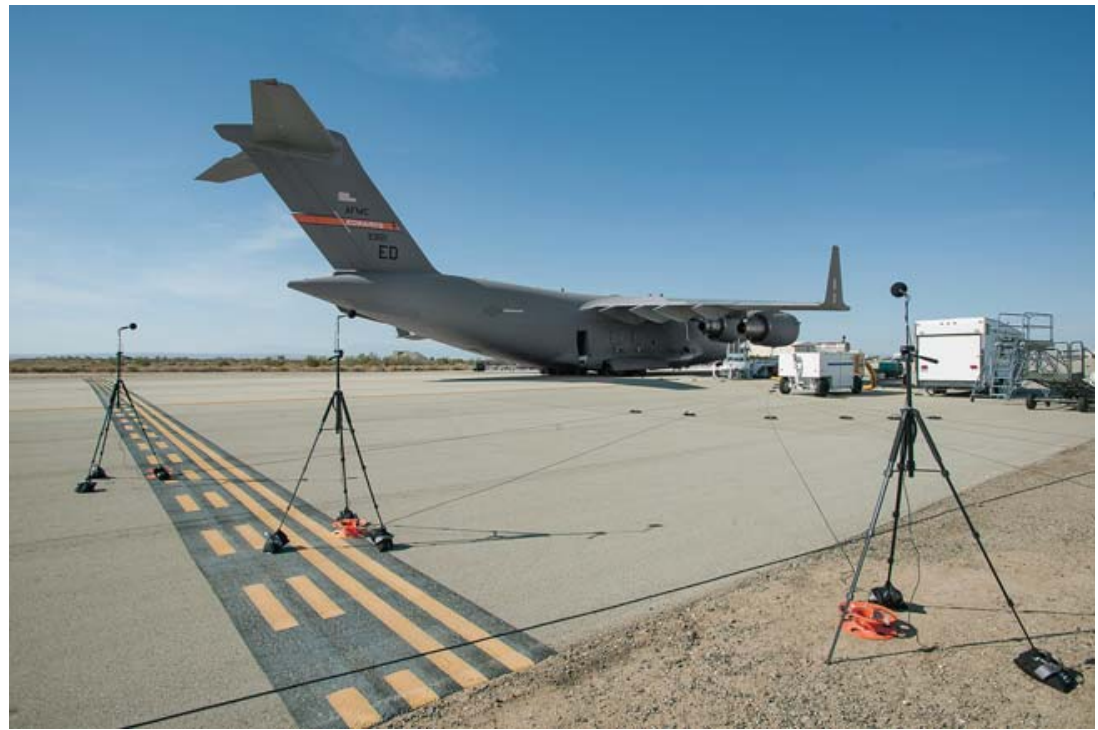

NASA Photograph ED13-0228-160 


\section{Research Engine}

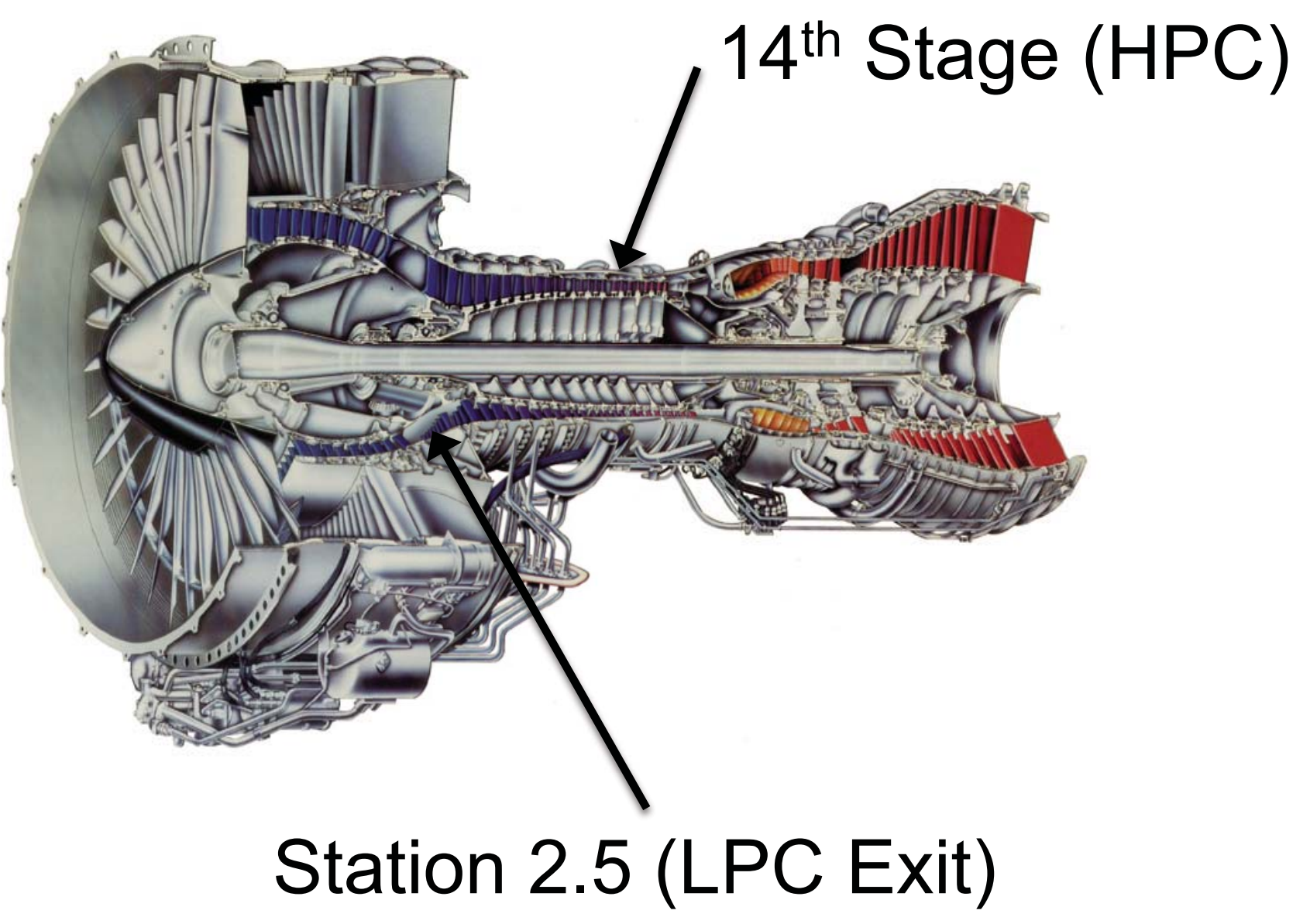




\section{Detection of $14^{\text {th }}$ Stage Bleed Valve Fault}

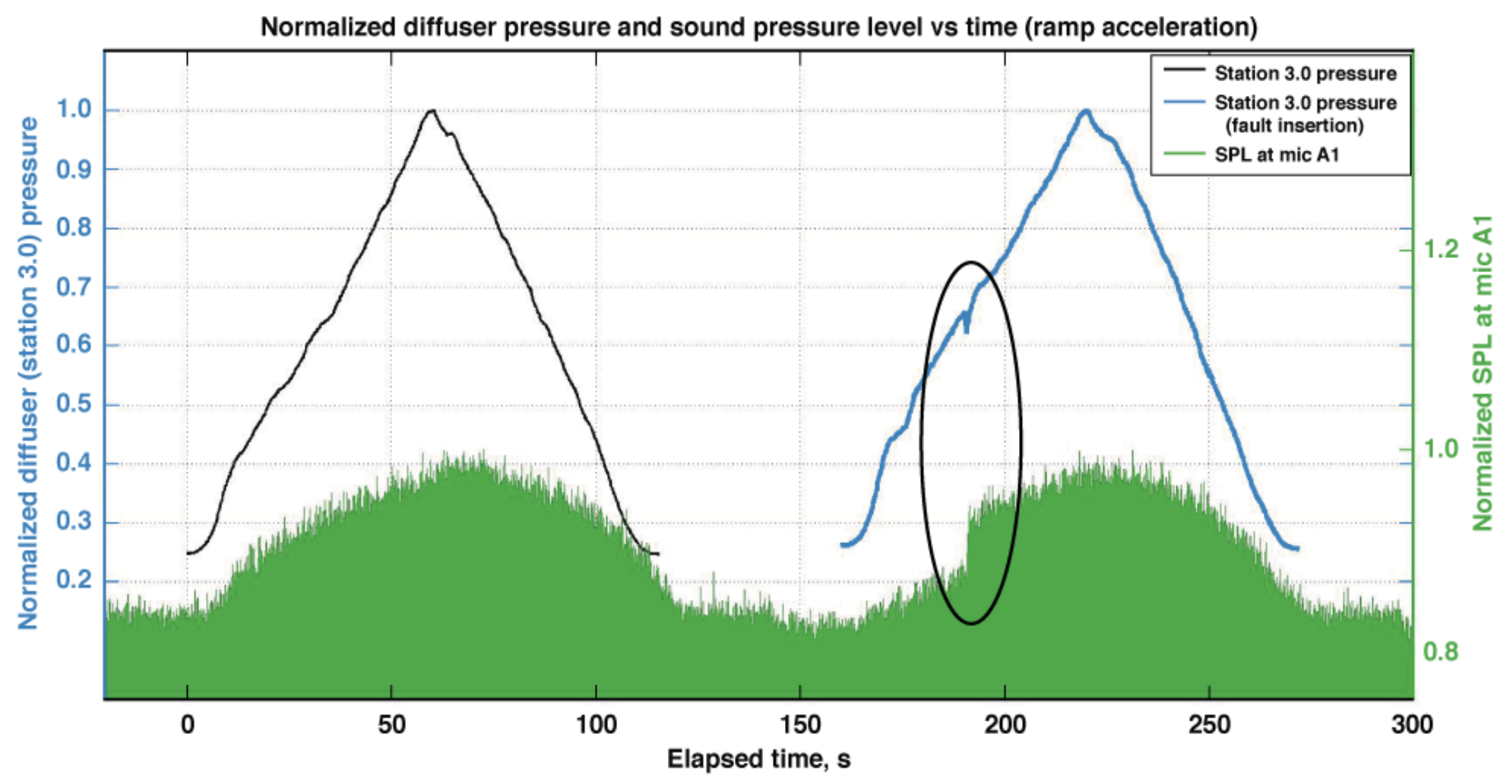

- Ramp Acceleration (approx. 1 min. from idle to target power) for normal and fault insertion 


\section{Detection of $14^{\text {th }}$ Stage Bleed Valve Fault}

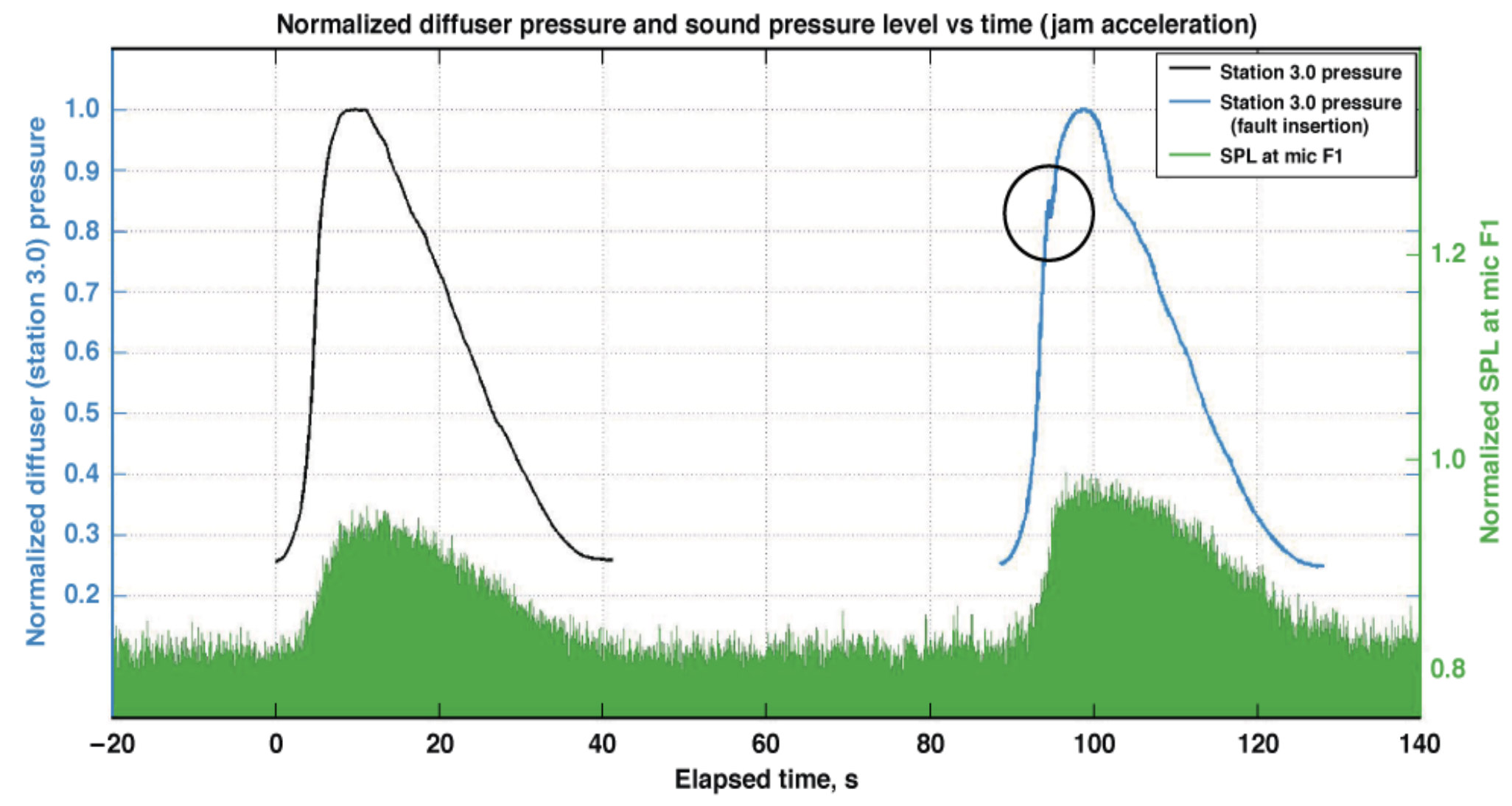

- Jam Acceleration (rapidly from idle to target power) for normal and fault insertion 


\section{Detection of $14^{\text {th }}$ Stage Bleed Valve Fault}

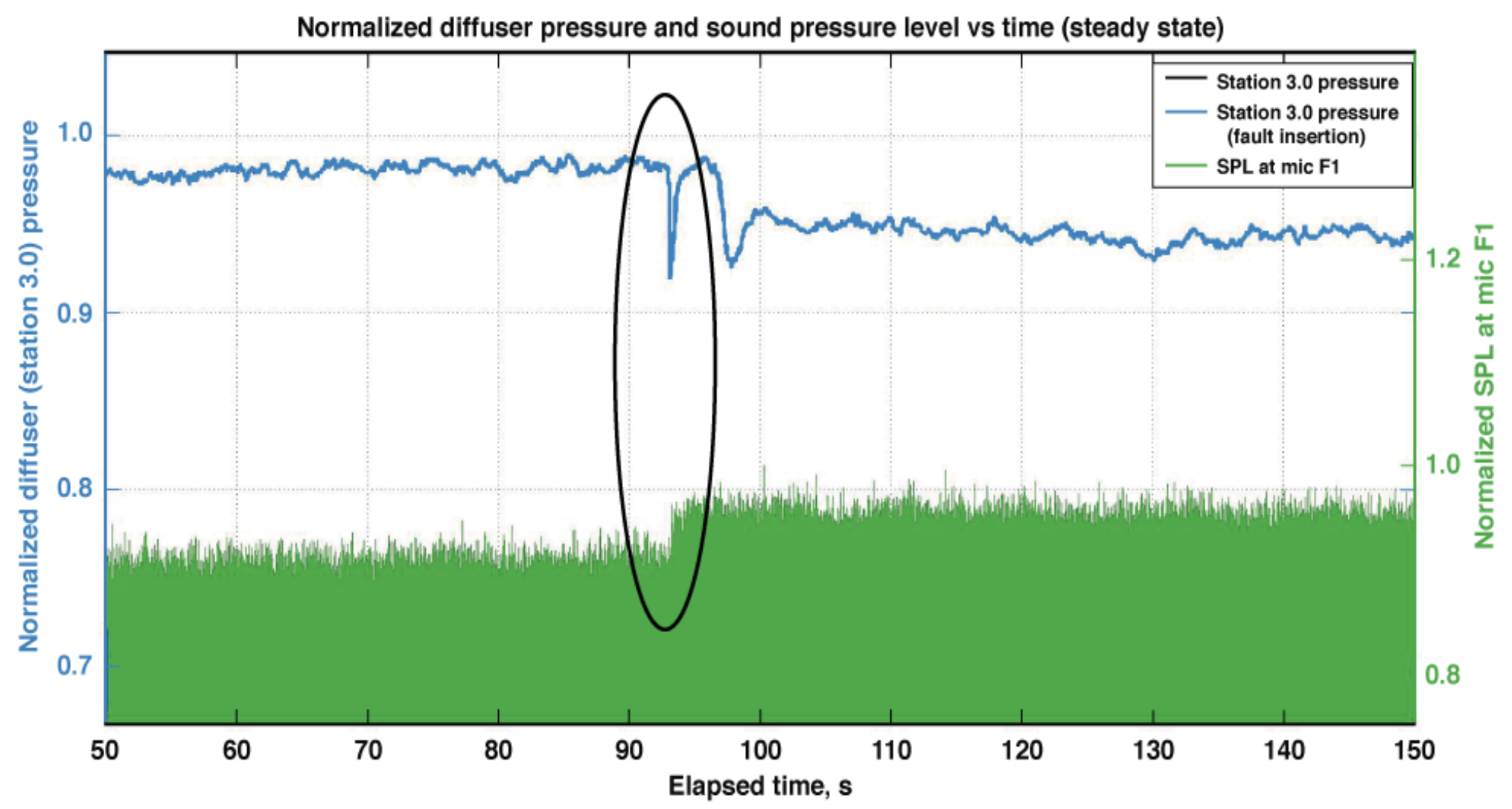

- Engine steady operation for normal and fault insertion 


\section{Station 2.5}

- Detection of the seeded faults of the station 2.5 proved troublesome

- Several factors contributed to this:

-Pressure at the $14^{\text {th }}$ stage bleed valve is an order of magnitude greater than at station 2.5

-Station 2.5 modulates as the engine transitions between idle and max power, whereas $14^{\text {th }}$ stage valve is discrete (fully closed to "failed" fully open)

- All of these factors suggest that the magnitude of the noise resulting from the failure of the station 2.5 valve was much lower than from the $14^{\text {th }}$ stage 


\section{Anticipated Future Work}

- A greater variety of failures is expected for VIPR III testing (Summer 2015)

- Volcanic ash ingestion offers a tremendous opportunity to detect subtle changes (degradation) to engine performance

- More bleed valve simulated failures

- Injection of oil simulating failure of forward bearing seal

- Further analysis of current data set 


\section{Conclusion}

- Preliminary analysis of simulated failure of $14^{\text {th }}$ stage bleed valve to its failsafe position suggests feasibility of far field acoustic microphone array to detect the fault

- Fault of station 2.5 bleed valve proved more difficult to detect due to the circumstances

- The results offer justification for continuation of work in this area 


\section{Acknowledgements}

- NASA Armstrong Flight Research Center (formerly Dryden Flight Research Center) Center Innovation Fund provided funding for procurement and labor

- Several employees helped in the somewhat arduous setup and takedown process during testing

- Bruel \& Kjaer representative from Southern California offered advice on test setup 


\section{Questions?}
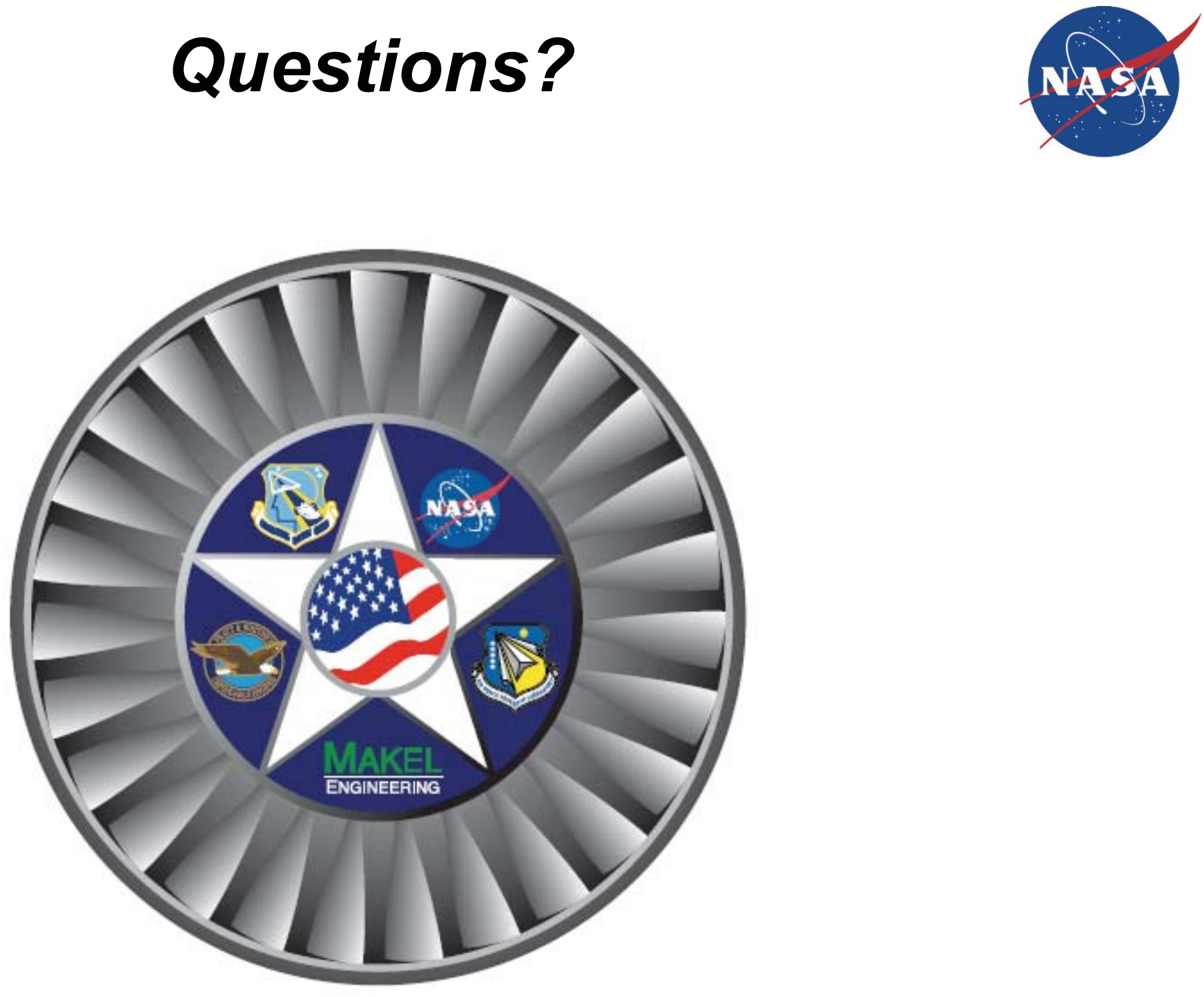